\title{
REVIEW OF SMALL CELL CARCINOMA OF THE KIDNEY WITH FOCUS ON CLINICAL AND PATHOBIOLOGICAL ASPECTS
}

\author{
Naoto Kuroda ${ }^{1}$, Yoshiaki Imamura ${ }^{2}$, Takeru Hamashima ${ }^{3}$, Chisato Ohe ${ }^{4}$, Shuji Mikami 5 , \\ Yoji Nagashima ${ }^{6}, \mathrm{Keiji}_{\text {Inoue}}{ }^{7}$, Delia Perez-Montiel ${ }^{8}$, Fredrik Petersson $^{9}$, Michal Michal $^{10}$, \\ OndReJ Hes ${ }^{10}$
}

\author{
${ }^{1}$ Department of Diagnostic Pathology, Kochi Red Cross Hospital, Kochi, Japan \\ ${ }^{2}$ Division of Surgical Pathology, University of Fukui Hospital, Fukui, Japan \\ ${ }^{3}$ Department of Pathology, Graduate School of Medicine and Pharmaceutical Sciences, University of Toyama, Toyama, Japan \\ ${ }^{4}$ Department of Pathology, Kansai Medical University Hirakata Hospital, Osaka, Japan \\ ${ }^{5}$ Division of Diagnostic Pathology, Keio University Hospital, Tokyo, Japan \\ ${ }^{6}$ Department of Molecular Pathology, Yokohama City University Graduate School of Medicine, Yokohama, Japan \\ ${ }^{7}$ Department of Urology, Kochi Medical School, Kochi University, Kochi, Japan \\ ${ }^{8}$ Department of Pathology, National Institute of Cancer of Mexico, Mexico City, Mexico \\ ${ }^{9}$ Department of Pathology, National University Hospital System, Singapore, Singapore \\ ${ }^{10}$ Department of Pathology, Medical Faculty Hospital, Charles University, Plzen, Czech Republic
}

\begin{abstract}
Small cell carcinoma (SmCC) of the kidney is extremely rare. In this article, we present a review of SmCC of the kidney with the focus on clinical and pathobiological aspects. Macroscopically, this tumor often shows a bulky mass extensively replacing the renal parenchyma with vascular invasion and metastasis to lymph nodes. Histologically, the tumor is composed of small cells with scant cytoplasm, round to oval nuclei, finely granular chromatin and inconspicuous nucleoli. Rosette or tubular formation may be present. Immunohistochemically, neoplastic cells show variable positivity for neuron-specific enolase, chromogranin A, synaptophysin, CD57 (Leu7) and CD56. A dot-like staining pattern for cytokeratin may also be observed. An electron microscopic examination may identify electron-dense neurosecretory granules in the cytoplasm. As a therapeutic option, nephrectomy and systemic chemotherapy should be considered. However, despite multimodal therapy, most patients have a dismal outcome and die of widely metastatic disease within one to two years. As there are limited genetic data on SmCC of the kidney, a large series studying this will be needed in the future.
\end{abstract}

Key words: small cell carcinoma, kidney, dismal prognosis.

\section{Introduction}

Small cell carcinoma (SmCC) predominantly occurs in the lung, but may arise in a wide variety of organs. Primary renal SmCC is an extremely rare neoplasm. According to the present World Health Organization (WHO) classification of the lung, neuroendocrine tumors are subdivided into four categories: (1) typical carcinoid, (2) atypical carcinoid, (3) small cell and (4) large cell neuroendocrine carcinoma (LCNEC) [1]. All these tumors have also been reported in the kidney [25]. In this article, we present an overview of SmCC of the kidney with clinical and pathobiological aspects.

\section{Clinical characteristics}

Clinical data of 31 previously reported cases of SmCC of the kidney are summarized in Table I. Some 
Table I. Clinicopathological data of 31 previously reported cases of small cell carcinoma of the kidney

\begin{tabular}{|c|c|}
\hline Sex & Male : female $=14: 17$ \\
\hline Age & $22-87$ years (mean 57 years) \\
\hline \multirow[t]{4}{*}{ Follow-up } & 27 cases available \\
\hline & 18 died of disease \\
\hline & 2 alive with disease \\
\hline & 7 alive without disease \\
\hline \multirow{6}{*}{$\begin{array}{l}\text { Immunohisto- } \\
\text { chemistry } \\
\text { (positive/exam- } \\
\text { ined) }\end{array}$} & Neuron specific enolase $7 / 9$ \\
\hline & Chromogranin A 11/14 \\
\hline & Synaptophysin $12 / 13$ \\
\hline & Cytokeratin CAM5.2 12/13 \\
\hline & TTF-1 $1 / 1$ \\
\hline & CD56 1/1 \\
\hline
\end{tabular}
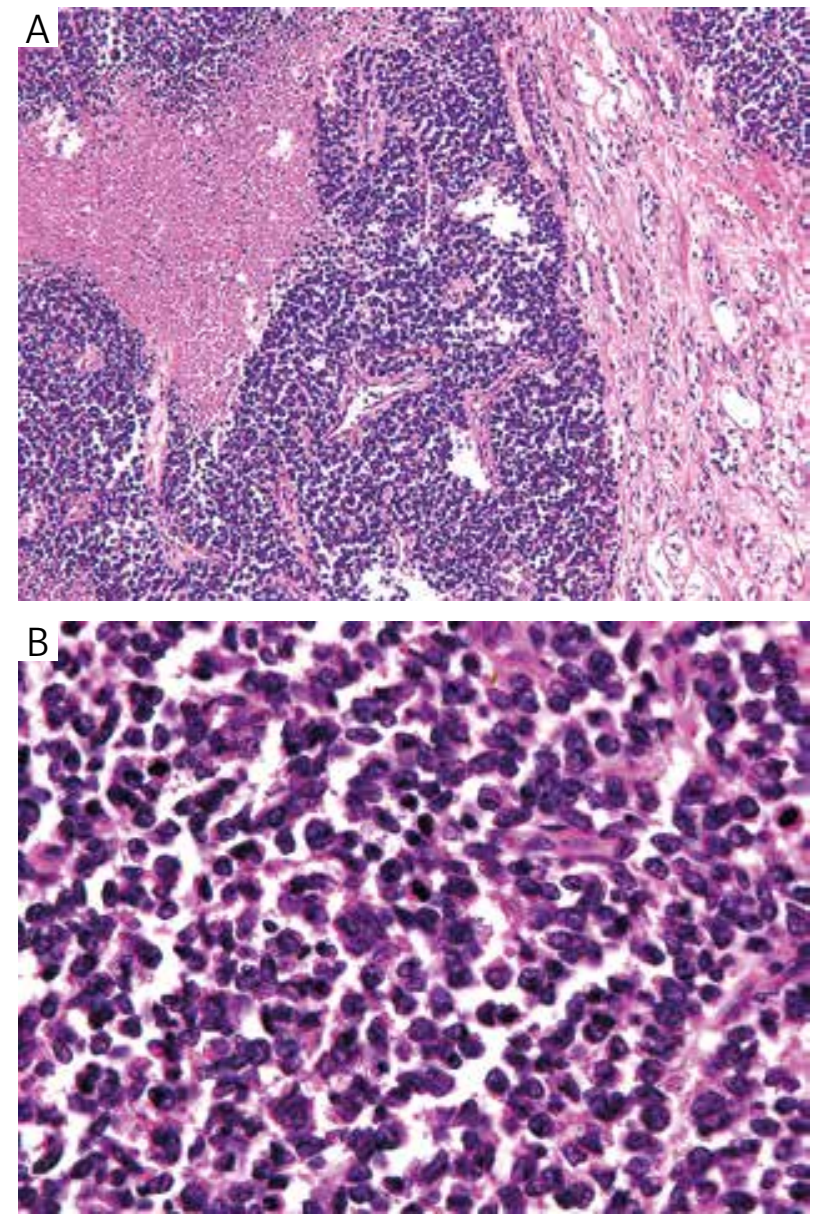

Fig. 1. Microscopic findings. A) Sheet-like growth pattern with extensive necrosis is seen. B) The size of tumor cells is not larger than three times that of resting lymphocytes. Nuclear chromatin is finely granular and nucleoli are inconspicuous investigators have reported a female preponderance whereas other studies suggest that there is no gender predominance [3, 6-8]. Patients frequently present with abdominal pain, gross hematuria, flank mass and weight loss [3, 6-10]. A smoking history is present in some cases [2]. Imaging analysis may disclose a large heterogeneous renal mass frequently with extension into the renal vein or inferior vena cava and/ or metastasis to lymph nodes $[7,11]$. An association with papillary RCC and chromophobe RCC has been reported $[2,12]$. Small cell carcinoma with foci of glandular or squamous differentiation seems to be restricted to tumors that arise from the renal pelvis, but not from renal parenchyma $[8,13]$. Primary renal SmCC arising after renal transplantation has been reported [14].

\section{Pathological findings \\ Macroscopic findings}

The tumor usually presents as a huge mass when discovered, and extends into the perinephric adipose tissue [3, 6-11, 15]. The cut surface of the tumor shows white, gray-white or gray-yellow color $[10,16$, 17]. Multilobulation is frequently seen [18]. Invasion into the inferior vena cava or renal vein and metastasis to lymph nodes are frequent $[3,6,7,10,11,15]$. Direct invasion into adjacent anatomical structures such as liver, diaphragm or abdominal wall may be observed $[2,6,17]$.

\section{Microscopic findings}

The tumor consists of small neoplastic cells with a size of up to three times as large as a small, nonstimulated/resting lymphocyte $[6,10,17]$. Several growth patterns such as solid-sheet, nesting, trabecular, rosette or tubular formation may be seen [17]. Extensive necrosis is often present (Fig. 1A) $[2,3,8]$. Nuclear molding and/or smudging of the chromatin, as seen in the pulmonary SmCC, are common features [8]. Tumor cells possess scant cytoplasm, oval to round nuclei, finely granular nuclear chromatin, and absent to inconspicuous nucleoli (Fig. 1B) [3, 6, $8,9,15-17,19]$. Mitotic activity is brisk and atypical mitotic figures are frequent $[6,15,17]$.

\section{Histochemical findings}

The cytoplasm of tumorous cells demonstrates positivity for the argyrophilic Grimelius stain [15, 17, 19]. Argentaffin Fontana-Masson silver impregnation stain is generally negative $[9,16]$.

\section{Immunohistochemical findings}

Neoplastic cells show variable positivity for neuron-specific enolase, chromogranin A, synaptophysin, 
CD57 (Leu 7) and CD56 [2, 3, 6, 8-11, 16, 18-20]. In addition, tumor cells frequently demonstrate dotlike staining for cytokeratin (Fig. 2) [3, 20]. In some cases, immunoreactivity to hormonal polypeptides including calcitonin, serotonin and adrenocorticotropic hormone has been documented [3, 6, 15]. The main immunohistochemical data are summarized in Table I.

\section{Ultrastructural findings}

Tumor cells contain electron-dense neurosecretory granules, mitochondria, endoplasmic reticulum, Golgi apparatus, polyribosomes and intermediate filaments in the cytoplasm $[6,16,19,20]$. Intercellular junctions with features suggesting desmosomes may be observed $[3,9,20]$.

\section{DNA flow cytometry}

DNA analysis of the tumor cells shows an aneuploidy peak $[9,17]$.

\section{Molecular genetic study}

In a case with combined renal SmCC and papillary RCC, fluorescence in situ hybridization analysis showed the amplification of the $M y c$ gene [21].

\section{Differential diagnosis}

Renal SmCC should be discriminated from typical carcinoid, atypical carcinoma, LCNEC, high grade urothelial carcinoma, small cell oncocytoma with pseudorosettes (SCOP), thyroid-like follicular carcinoma of the kidney, blastemal-dominant Wilms' tumor, Ewing's sarcoma/primitive neuroectodermal tumor (ES/PNET), neuroblastoma, malignant lymphoma, rhabdomyosarcoma (RMS), desmoplastic small round cell tumor (DSRCT), synovial sarcoma (SS) and metastatic SmCC. Tumor cells of typical carcinoid are arranged in trabecular, ribbon-like, gyriform, insular, glandular and solid patterns, but mitotic figures are sparse [5]. In atypical carcinoid, increased mitotic activity is observed [22]. The size of tumor cells in LCNEC is larger than that of SmCC. Abundant cytoplasm, vesicular chromatin, prominent nucleoli and perilobular palisading are seen $[2-$ $4,18]$. High grade urothelial carcinoma including the plasmacytoid variant or lymphoepithelioma-like variant should be distinguished from SmCC [23]. Neoplastic cells of SCOP consist of oncocytes and oncoblasts surrounding hyaline-basement membrane-like material [24]. Thyroid-like follicular carcinoma has follicular architecture composed of microfollicles and macrofollicles filled with colloid-like material [25]. Wilms' tumor predominantly occurs in children and the blastemal component is positive for WT1 [26]. Ewing's sarcoma/primitive neuroectodermal tumor is

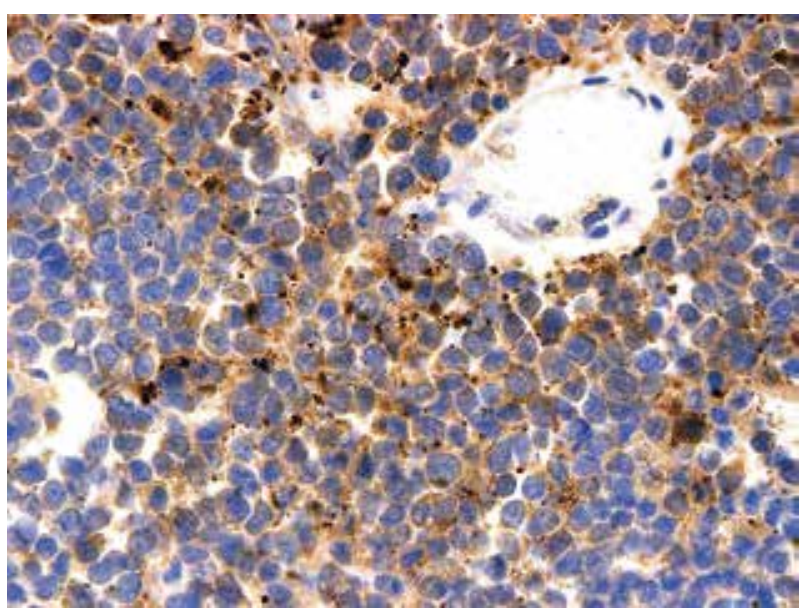

Fig. 2. Immunohistochemical findings. The cytoplasm of neoplastic cells shows a dot-like staining pattern for cytokeratin CAM5.2

immunohistochemically positive for CD99 and Fli-1. The identification of a chimeric transcript specific for ES/PNET is diagnostically useful [26]. Malignant lymphoma has cleaved, convoluted or lobulated nuclei and is generally immunoreactive for CD45 (leukocyte common antigen). Neuroblastoma generally occurs in the adrenal gland and histologically has a delicate cytoplasmic process. Rhabdomyosarcoma generally affects infants or children and tumor cells display eosinophilic or clear cytoplasm and may show striation. Rhabdomyosarcoma is positive for desmin, myogenin or Myo D1. Desmoplastic small round cell tumor generally occurs in children and adolescents and is immunohistochemically positive for WT1 and desmin. The detection of EWS-WT1 chimeric transcript is very helpful in establishing the accurate diagnosis [27]. Synovial sarcoma is immunohistochemically positive for CD99 and bcl-2. The identification of a chimeric transcript such as SYT-SXX1 or SYT$S X X 2$ is diagnostic for this tumor [28]. Finally, it is for clinicians to exclude the possibility of metastatic cancer, particular SmCC derived from the lung [9, 17]. In this situation, TTF-1 immunohistochemistry is not helpful in determining the primary site, because TTF-1 is generally expressed in SmCC of various anatomic sites. Accordingly, the clinical information is most important in establishing the differential diagnosis whether the tumor is primary or metastatic.

\section{Therapy}

Surgical resection by nephrectomy and systemic chemotherapy is the currently available therapeutic modality $[7,9,16,29,30]$. Nephrectomy helps to establish the correct diagnosis, i.e. to rule out other more common renal neoplasms within the spectrum of malignant small round blue cell tumors [10]. However, as renal SmCC often shows extra-renal extension, the tumor may be amendable to com- 
plete resection [18]. Regarding chemotherapy, platinum-based chemotherapy improves overall survival [7]. Tumor thrombectomy may be effective [10]. Radiation therapy can be used for postoperative residual local disease or metastatic lesions $[18,20]$.

\section{Prognosis}

Patients usually have a poor clinical outcome despite multimodal therapy $[2,6-8,18,20,30]$. Most patients die of the disease within a few years $[7,8]$. Distant metastasis occurs in the brain, bone, lung, liver and adrenal gland $[2,3,6,8,16,17,20,30]$. It is possible that patients with organ-confined tumor may have a long-term survival with early discovery and treatment [8].

\section{Future perspectives}

Owing to the rarity of this tumor, there is a limited amount of genetic data on renal SmCC to date. Accordingly, a large scale genetic study is necessary to elucidate the pathogenesis of this tumor. According to the WHO classification of tumors of the digestive tract, the grading of neuroendocrine neoplasm is based on mitotic counts and the Ki-67 index. According to this scheme, neuroendocrine epithelial neoplasms have been subdivided into neuroendocrine tumor (NET) G1, NET G2 and neuroendocrine carcinoma (large cell and small cell types) [31]. It is possible that neuroendocrine neoplasm arising from the kidney may follow the classification of other organs such as the digestive or respiratory tract in the near future $\{1,31\}$.

\section{Authors declare no conflict of interest.}

\section{References}

1. Travis WD. The concept of pulmonary neuroendocrine tumours: In: World Health Organization Classification of Tumours. Pathology \& Genetics. Tumours of the Lung, Pleura, Thymus and Heart. Travis WD, Brambillia E, Muller-Hermelink HK, Haris CC (eds). IARC Press, Lyon 2004; 19-20.

2. Lane BR, Chery F, Jour G, et al. Renal neuroendocrine tumours: a clinicopathological study. BJU Int 2007; 100: 10301035 .

3. Mazzucchelli R, Morichetti D, Lopez-Beltran A, et al. Neuroendocrine tumours of the urinary system and male genital organs: clinical significance. BJU Int 2009; 103: 1464-1470.

4. Ratnagiri R, Singh SS, Majhi U, et al. Large-cell neuroendocrine carcinoma of the kidney: clinicopathologic features. Indian J Urol 2009; 25: 274-275.

5. Kuroda N, Tanaka A, Ohe C, et al. Review of renal carcinoid tumor with focus on clinical and pathobiological aspects. Histol Histopathol 2013; 28: 15-21.

6. Têtu B, Ro JY, Ayala AG, et al. Small cell carcinoma of the kidney. A clinicopathologic, immunohistochemical, and ultrastructural study. Cancer 1987; 60: 1809-1814.

7. Majhail NS, Elson P, Bukowski RM. Therapy and outcome of small cell carcinoma of the kidney. Report of two cases and a systemic review of the literature. Cancer 2003; 97: 1436-1441.
8. Si Q, Dancer J, Stanton ML, et al. Small cell carcinoma of the kidney: a clinicopathologic study of 14 cases. Hum Pathol 2011; 42: 1792-1798.

9. González-Lois C, Madero S, Redondo P, et al. Small cell carcinoma of the kidney. A case report and review of the literature. Arch Pathol Lab Med 2001; 125: 796-798.

10. Xu G, Chen J, Zhang Z. Primary small cell carcinoma of the kidney with tumor thrombus extension into inferior vena cava and pulmonary artery: a case report and review of the literature. J Int Med Res 2009; 37: 587-593.

11. Karadeniz-Bilgili MY, Semelka RC, Hyslop WB, et al. MRI findings of primary small-cell carcinoma of kidney. Magn Reson Imaging 2005; 23: 515-517.

12. Mackey JR, Au HJ, Hugh J, Venner P. Genitourinary small cell carcinoma: determination of clinical and therapeutic factors associated with survival. J Urol 1998; 159: 1624-1629.

13. Kitamura M, Miyanaga T, Hamada M, et al. Small cell carcinoma of the kidney: case report. Int J Urol 1997; 4: 422-424.

14. Lee HY, Wu WJ, Tsai KB, et al. Primary small cell carcinoma of kidney after renal transplantation: a case report and literature review. Chin J Cancer Res 2013; 25: 608-611.

15. Capella C, Eusebi V, Rosai J. Primary oat cell carcinoma of the kidney. Am J Surg Pathol 1984; 8: 855-861.

16. Yu DS, Chang SY, Wang J, et al. Small cell carcinoma of the urinary tract. Br J Urol 1990; 66: 590-595.

17. Kilicarsalan Akkaya B, Mustafa U, Esin O, et al. Primary small cell carcinoma of the kidney. Urol Oncol 2003; 21: 11-13.

18. Lane BR, Jour G, Zhou M. Renal neuroendocrine tumors. Indian J Urol 2009; 25: 155-160.

19. Masuda T, Oikawa H, Yashima A, et al. Renal small cell carcinoma (neuroendocrine carcinoma) without features of transitional cell carcinoma. Pathol Int 1998; 48: 412-415.

20. Morgan KG, Banerjee SS, Eyden BP. Primary small cell neuroendocrine carcinoma of the kidney. Ultrastruct Pathol 1996; 20: 141-144.

21. La Rosa S, Bernasconi B, Micello D, et al. Primary small cell neuroendocrine carcinoma of the kidney: morphologic, immunohistochemical, ultrastructural, and cytogenetic study of a case and review of the literature. Endocr Pathol 2009; 20: 24-34.

22. Aung PP, Killian K, Poropatich CO, et al. Primary neuroendocrine tumors of the kidney: morphological and molecular alterations of an uncommon malignancy. Hum Pathol 2013; 44: 873-880.

23. Perez-Montiel D, Wakely PE, Hes O, et al. High-grade urothelial carcinoma of the renal pelvis: clinicopathologic study of 108 cases with emphasis on unusual morphologic variants. Mod Pathol 2006; 19: 494-503.

24. Petersson F, Síma R, Grossman P, et al. Renal small cell oncocytoma with pseudorosettes. A histomorphologic, immunohistochemical, and molecular genetic study of 10 cases. Hum Pathol 2011; 42: 1751-1760.

25. Amin MB, Gupta R, Ondrej $\mathrm{H}$, et al. Primary thyroid-like follicular carcinoma of the kidney: report of 6 cases of a histologically distinctive adult renal epithelial neoplasm. Am J Surg Pathol 2009; 33: 393-400.

26. Jimenez RE, Folpe AL, Lapham RL, et al. Primary Ewing's sarcoma/primitive neuroectodermal tumor of the kidney. A clinicopathologic and immunohistochemical analysis of 11 cases. Am J Surg Pathol 2002; 26: 320-327.

27. Wang LL, Perlman EJ, Vujanic GM, et al. Desmoplastic small round cell tumor of the kidney in childhood. Am J Surg Pathol 2007; 31: 576-584.

28. Argani P, Faria PA, Epstein JI, et al. Primary renal synovial sarcoma: molecular and morphologic delineation of an entity previously included among embryonal sarcoma of the kidney. Am J Surg Pathol 2000; 24: 1087-1096.

29. Lo Re G, Canzonieri V, Veronesi A, et al. Extrapulmonary small cell carcinoma: A single-institution experience and review of the literature. Ann Oncol 1994; 5: 909-913. 
30. Kim JH, Lee S-H, Park J, et al. Extrapulmonary small-cell carcinoma: a single-institution experience. Jpn J Clin Oncol 2004; 34: 250-254.

31. Rindi G, Klimstra DS, Arnold R, et al. Nomenclature and classification of neuroendocrine neoplasm of the digestive system: In: World Health Organization classification of Tumours of the Digestive System. $4^{\text {th }}$ ed. Bosman FT, Carneiro F, Hruban RH, Theise ND (eds.). IARC Press, Lyon 2010; 13-14.

\section{Address for correspondence}

\section{Naoto Kuroda}

Department of Diagnostic Pathology

Kochi Red Cross Hospital, Shin-honmachi 2-13-51

Kochi City, Kochi 780-8562, Japan

tel. $+81-88-822-1201$

fax $+81-88-822-1056$

e-mail:kurochankochi@yahoo.co.jp 